\title{
Reinterpretando la responsabilidad ambiental por daños a las personas derivados de actividades riesgosas: el caso de los contratos agroindustriales
}

\author{
Guillermo Gapel Redcozub* \\ Haraví Eloisa Ruiz**
}

\begin{abstract}
RESUMEN
Los contratos agroindustriales en Argentina se han convertido en un instrumento de extensa difusión para coordinar la producción de una gran variedad de frutos primarios destinados a procesos de industrialización, caracterizándose por contener ciertas cláusulas que otorgan amplias facultades de dirección y control del proceso a favor del empresario industrial o comerciante (empresarios integradores). En estos casos, cuando en el marco de las tareas productivas el productor integrado lleve a cabo actividades riesgosas o peligrosas que ocasionen daños ambientales indirectos, los empresarios integradores serán pasibles de responsabilidad ambiental en virtud de su carácter de servidos de la actividad riesgosa, con independencia del provecho económico que le pueda reportar el producido de dichas actividades. Esta extensión de responsabilidad se fundamenta en la reinterpretación del art. 1758 in fine del CCCN, efectuada en forma armónica con el art. 41 de la Constitución Nacional, con la legislación especial en la materia (Ley General del Ambiente), y con las normas civiles relativas a la función preventiva del derecho de daños.
\end{abstract}

Contratos agroindustriales - daños ambientales - responsabilidad por actividades riesgosas o peligrosas

\section{Production contracts and environmental liability of processors due to dangerous activities carried by farmers}

\begin{abstract}
Production Contracts have become a widely used tool to coordinate the production of commodities for industrial purposes in Argentina. As a remarkable feature, these contracts allow industrial
\end{abstract}

* Abogado y Licenciado en Economía, Universidad Nacional del Nordeste, Argentina. Master of Laws, Harvard Law School, Estados Unidos. Profesor Titular Regular de Derechos Reales, Facultad de Derecho y Ciencias Sociales, Universidad del Nordeste, Argentina. Correo electrónico: guillermogapel@gmail.com ** Abogada, Facultad de Derecho y Ciencias Sociales, Universidad Nacional del Nordeste (UNNE, Argentina).Becaria doctoral Conicet.Correo electrónico: haraviruiz@gmail.com

Artículo recibido el 30.3.2016 y aceptado para su publicación el 10.7.2017. 
firms ("processors") to manage and supervise the commodities production process, turning farmers and small agricultural enterprises into mere providers of services. Under this relationship, when farmers perform dangerous activities guided and monitored by processors and those activities cause certain type of environmental damages, the former can be beld liable and required to compensate the victims. This liability rule is built upon the provisions of the new Argentine Civil and Commercial Code, the General Law for the Environment and the National Constitution.

Production Contracts - Environmental Damages - Liability for Dangerous Activities

\section{INTRODUCCIÓN}

$\mathrm{E}$ n forma cada vez más acentuada y en especial en relación con ciertos productos, la actividad de los agricultores se inserta en el cuadro de lo que se denomina "complejo agroindustrial"1. A tal punto es así que algunos economistas y sociólogos agrarios plantean la distinción entre productores agrícolas "excluidos" e "integrados" al complejo agroindustrial, en el que la planificación concatenada del proceso productivo va desde la provisión de insumos al productor primario, hasta la colocación del producto final en las bocas de expendio a disposición de los consumidores ${ }^{2}$.

Como señalan Teubal y Pastore ${ }^{3}$, estos complejos agroindustriales existen en Argentina desde la época de la revolución industrial. Los llamados "cultivos industriales" - aquellos que necesariamente deben pasar por un proceso de industrialización- como la caña de azúcar, la vid o la yerba mate, forman parte de estos sistemas desde hace muchos años, mientras que otros cultivos han mutado hacia este perfil en la década de los noventa, tal es el caso del complejo lácteo, la avicultura, la cebada y las oleaginosas, entre otros.

En el contexto de esta lógica productiva, los contratos agroindustriales se han convertido en un instrumento legal de amplia difusión para coordinar la producción de una gran variedad de frutos primarios destinados a procesos de industrialización, principalmente en aquellos casos de productos finales altamente específicos.

${ }^{1}$ Este término hace referencia a la creciente interrelación sectorial entre la agricultura, la industria y los servicios, a un conjunto de relaciones de encadenamiento, coordinación o control entre sus elementos, ya sean miembros, componentes o etapas de un proceso. La expresión "Complejo Agroindustrial" ha sido asociada y usada de manera indistinta con las voces Agribussiness, Cadena Agroindustrial y Filière, aun cuando cada una de ellas posee estrictamente una carga conceptual y valorativa diversa, aunque aplicados al mismo fenómeno (Da Silva, J. G., "Complejos Agroindustriales y Otros Complejos”, en Revista Brasileña Reforma Agraria, No3 Vol. 21, septiembre-diciembre de 1991, pp. 205-206).

${ }^{2}$ Casella, A. P., Modalidades Negociales de la Empresa Agraria en el Marco del Complejo Agroindustrial y Agroalimentario: Contratos Agroindustriales y Acuerdos Interprofesionales. Comunicaciones Científicas y Tecnológicas de la UNNE, Universidad Nacional del Nordeste, Corrientes, 2001, pp. 1-2. Disponible en: http://www1. unne.edu.ar/cyt/2001/1-Sociales/S-024.pdf. Último acceso: 3 de marzo de 2016.

${ }^{3}$ Teubal, M. y Pastore R., "El Agro y los Complejos Agroindustriales: el caso argentino”, en Teubal, M. (Dir), en Globalización y expansión agroindustrial ¿Superación de la pobreza en América Latina?, Ed. Corregidor, Buenos Aires, 1995, pp. 107-135. 
Estos contratos, conocidos también como contratos de integración o de integración agroindustrial (Moruzzi ${ }^{4}$, Bivona ${ }^{5}$, Iannarelli ${ }^{6}$, Germanò $^{7}$, Watanabe ${ }^{8}$, Domenèch ${ }^{9}$, Carroza y Zaledón Zeledón ${ }^{10}$, en la doctrina extranjera, y Brebbia y Malanos ${ }^{11}$, Casella ${ }^{12}$, Formento y Pilatti ${ }^{13}$ entre los más representativos de la doctrina local), o como contratos de producción (denominación dada por la legislación y autores norteamericanos como Hamilton ${ }^{14}$, Kelley ${ }^{15}$, Peck ${ }^{16}$, entre otros), poseen una larga trayectoria en Estados Unidos, Francia, España e Italia, donde desde hace décadas cuentan con regulaciones específicas y han adquirido un importante desarrollo.

Sin embargo, el incremento de su uso así como el aumento de su complejidad estructural es un fenómeno de manifestación relativamente reciente en Argentina (y Latinoamérica en general), lo que no ha impedido que la figura contractual alcance importantes niveles de adopción en ciertos subsectores económicos altamente integrados,

${ }^{4}$ Moruzzi, L., Profili della vendita di prodotti agricoli con Prezzo a riferimetno e contratto di integrazione verticale, Giufrè Ed, Milano, 1962, pp. 61-62.

${ }^{5}$ Bivona, G., I contratti d'integrazione verticale in agricoltura, Giuffrè Editore, Milano, 1979, pp. 2-4.

${ }^{6}$ Iannarelli, A. "Le relazioni contrattuali tra agricoltura e idnsutria nella recente esperienza giuridica italiana”, en Massart, A. (dir.), Accordi Interprofesionali e contratti agroindustriali, ETS Editrice, Pisa, 1990, pp. 70-89.

${ }^{7}$ Germanò, A. "Sul contratto di cessione di prodotti Agricole e Alimentari", en Rivista Diritto e Giurisprudenza Agraria, Alimentare e dell ambiente, $\mathrm{N}^{\circ}$ 6, junio 2012, pp. 379-396. Disponible en: http:// dga.wpdemo.it/wp-content/uploads/2015/11/fascicolo-6-2012.pdf . Último acceso: 10 de mayo de 2015.

${ }^{8}$ Kassia W., "Relações Contratuais no Agribussiness", Tesis de Doctorado, Scuola Superiore di Studi e Perfezionamento Sant’ Ana, Pisa, 2007, pp. 199-230.

9 Domènech, G., Los Contratos de Integración Agroindustrial, Ediciones Cooperativas, Buenos Aires, 2010, pp. 103-136.

${ }^{10}$ Carroza, A. y Zeledón Zeledón, R., Teoría General e Institutos del Derecho Agrario, Editorial Astrea, Buenos Aires, 1990, pp. 309-330.

${ }^{11}$ Brebbia, F. y Malanos, N., Derecho Agrario, $2^{\circ}$ Reimpresión, Editorial Astrea, Buenos Aires, 2011, pp. 591-606.

12 Casella, A., op. cit. 4.

${ }^{13}$ Formento, S. y Pilatti, H., "Los Contratos Agroindustriales: su perfil jurídico". Ponencia presentada en el VII Congreso de Derecho Agrario Argentino, Octubre 2004, Bahía Blanca. Disponible en: http:// www.iadaweb.com.ar/eventos/anteriores/7 congresoarg 2004/Ultimas \%20tendencias\%20Constractuales $\% 20$ Agrarias/Los\%20contratos\%20Agroindustriales-Prof.Formento-Pilatti.doc . Último acceso 15 de junio de 2015. También en Formento, S. "Empresa Agraria y sus Contratos de negocios", Editorial Facultad de Agronomía, Universidad de Buenos Aires, Buenos Aires, 2005, pp. 139-163.

${ }^{14}$ Hamilton, N., "Farmer's Legal Guide to Production Contracts", Research Project, The National Agricultural Center. University of Arkansas. School of Law-Division of Agriculture, Arkansas, 1995. Disponible en: http://www.nationalaglawcenter.org/assets/articles/hamilton_productioncontracts.pdf, p. 2. Último acceso: 22 de noviembre de 2015.

${ }^{15}$ Kelley, C. R., “Agricultural production contracts: drafting considerations”, en The Hamline Law Review, Spring of 1995, Hamline University-Law School. Saint-Paul-MN, p. 2.

${ }^{16}$ Peck, A., "State regulation to Production Contracts", Research Project, The National Agricultural Law Center, University Of Arkansas, 2006. Disponible en: http://nationalaglawcenter.org/publication/view/ peck-state-regulation-of-production-contracts-national-aglaw-center-publications-2006/. Último Acceso: 1 de diciembre de 2015 . 
como sucede en los casos avícola subsector carne ${ }^{17}$, y en la cebada cervecera para malta ${ }^{18}$, entre otros.

Paralelamente a la expansión de las modernas modalidades de producción agropecuaria ${ }^{19}$, entre las que se destaca el fenómeno de la integración vía contratos agroindustriales, se percibe en los últimos años un incremento ostensible de conflictos ambientales que comprenden a graves casos de daños sufridos por personas, animales y el ambiente ${ }^{20}$. Estos conflictos generalmente tienen como uno de sus desencadenantes a las actividades productivas llevadas a cabo en explotaciones agropecuarias, muchas de estas llevan adelante sus actividades dentro de un esquema de integración basado en este tipo de contratación.

Sin perjuicio de las sanciones que puedan corresponder a quienes realizan directamente las actividades contaminantes ${ }^{21}$, y debido a que uno de los rasgos más característicos y novedosos de estos contratos es el traslado de las facultades de dirección y control sobre el proceso productivo al empresario industrial (o empresario integrador), nos proponemos reinterpretar el esquema responsabilidad civil a la luz de la nueva normativa del Código Civil y Comercial de la Nación (CCCN), y del bloque de legalidad compuesto por la Constitución Nacional $(\mathrm{CN})$, Tratados Internacionales y las leyes ambientales, con la finalidad de obtener una mejor respuesta jurídica frente al problema de los daños ambientales indirectos ocasionados por actividades productivas que se desarrollan al amparo de estos contratos agroindustriales.

${ }^{17}$ Palacios, P. Agroindustria Aviar Argentina, Ed. Imago Mundi, Buenos Aires, 2013. También en el Documento: “Complejo Avícola: Carne”, octubre 2011, Serie "Producción Regional por Complejos Productivos”. Secretaría de Política Económica. Subsecretaría de Producción Económica. Dirección Nacional de Programación Económica Regional. Ministerio de Economía y Finanzas Públicas. Disponible en: http:// www.mecon.gob.ar/peconomica/docs/Complejo_Avicola.pdf. Último Acceso: 20 de mayo de 2015.

18 Tommaso, J. C., "La cebada cervecera en la Argentina" en Revista IDIA XXI Revista de Información sobre Investigación y Desarrollo Agropecuario, INTA Bordenave, Buenos Aires, 2004, Nº, pp. 210 a 216. Disponible en: http://anterior.inta.gov.ar/ediciones/idia/cereales/cebada.htm. Último Acceso: 2/03/2015.

19 Teubal M. y Pastore R., op. cit. 5, enumeran entre las principales características de estas nuevas modalidades: el uso intensivo de insumos de carácter químico-industrial, como son los agroquímicos (pesticidas, y fertilizantes), de semillas OGM con restricciones derivadas de patentes por derechos de propiedad intelectual, la explotación capital-intensiva, y la tendencia a los monocultivos.

${ }^{20}$ Véanse los artículos del diario Clarín: "Mal uso y falta de control: El drama de los chicos que crecen en pueblos fumigados" (06/01/13), disponible en: http:/www.clarin.com/zona/Mal-uso-faltacontrol_0_842315859.html; diario La Nación: "El agua sube turbia en Junín” (19/03/2005), disponible en: http://www.lanacion.com.ar/687989-el-agua-sube-turbia-en-junin; diario Página 12: "Durmiendo con el pesticida" (27/03/2015), disponible en: http://www.pagina12.com.ar/diario/sociedad/3-269076-2015-03-27. html y "La salud cercada de Avia Terai" (20/05/2013), disponible en: http://www.pagina12.com.ar/diario/ sociedad/3-220393-2013-05-20.html; diario La Voz de Córdoba: "Fumigadores cordobeses tienen la salud alterada" (10/06/2015), disponible en: http://www.lavoz.com.ar/ciudadanos/fumigadores-cordobeses-tienenla-salud-alterada, entre muchos otros.

${ }^{21}$ En algunos de los casos más graves se han iniciado procesos penales contra productores agropecuarios y sus contratistas. Véase diario Página 12: "Al banquillo por rociar con glifosato" (03/12/2012), disponible en: http://www.pagina12.com.ar/diario/sociedad/3-209077-2012-12-03.html 
Iniciaremos esta tarea revisando las notas sobresalientes del contrato, luego distinguiremos las distintas clases de daños ambientales, continuaremos con la descripción de las posibles interpretaciones de los esquemas vigentes de responsabilidad ambiental por daños a terceros, entre las que incluiremos una versión de nuestra autoría, para luego avanzar en los fundamentos por los cuales entendemos que esta última postura se adapta mejor al citado bloque de legalidad. Finalmente, precisaremos cuál es la situación en la que se encuentra el empresario integrador como consecuencia de la celebración de un contrato agroindustrial.

\section{CARACTERIZACIÓN DEL CONTRATO}

El contrato agroindustrial no cuenta con una tipificación legislativa en Argentina, a diferencia de lo que sucede en los principales estados agrícolas de Estados Unidos ${ }^{22}$ y en varios países europeos como Francia ${ }^{23}$, Italia ${ }^{24}$ y España ${ }^{25}$. En este sentido, es importante destacar cierta uniformidad en la estructura de este contrato en todos los países ${ }^{26}$.

${ }^{22}$ Minnesota se convirtió en 1990 en el primer estado en regular estos contratos (sección 17, apartados 90 al 98 del Compendio de Leyes de Minnesota). En 1993 Wisconsin fue el segundo en legislarlo bajo la denominación de "contratos de adquisición de cultivos agrícolas" (secciones 101.01-101.07 de la Sección de Agricultura de su Código Administrativo). Kansas ha elegido legislar por separado los contratos de producción porcina (en 1994, ubicado en las secciones de 16-1501 a 16-1506) y los contratos de producción avícola (en 2002, en la sección 16-1701). También tienen leyes al respecto Illinois, Iowa y Arkansas.

${ }^{23}$ Según Brebbia F. y Malanos N. (op. cit. 11, pp. 599) fue en Francia donde este contrato adquiere tipicidad legal a partir de la década del 60 y citando a Confortini y Zimatore sostienen que la intervención más completa está plasmada en una ley de 1964, donde por primera vez se da la noción de contratos de integración. En igual sentido Domènech relata que el origen de la regulación de los contratos de integración en el derecho francés hay que situarla hace más de cuarenta años, en la iniciativa de la Ley núm. 64-678, del 6 de julio de 1964, y respecto de su naturaleza jurídica, sostiene que en el texto del "Code Rural" (artículo L326-1) se definen estos contratos, como contratos de integración (op. cit. 10, pp. 196-198).

${ }^{24}$ En el caso italiano, el contrato en estudio se reguló originalmente en la Ley No 88 , de 1988, titulada "Normas sobre acuerdos interprofesionales y sobre Contratos de Cultivación y Venta", de inspiración francesa. Posteriormente, se sanciona en el año 2005 el Decreto Ley $N^{\circ}$ 102, derogando la ley anterior. Este último, que lleva el nombre de "Relaciones del Mercado Agroalimentario" previó una completa modificación y mayor complejización del régimen anterior. Recientemente ha sufrido importantes reformas en el año 2012 mediante la Ley $\mathrm{N}^{\circ} 27$ (art. 62) y por el Decreto Ley 179 (art. 36), convertido en Ley $\mathrm{N}^{\circ} 221$.

25 Domènech señala que los contratos agroindustriales en España son mencionados por primera vez en la Ley 152/63 sobre "Industrialización de Interés Preferente", no obstante, la regulación más completa llegará con la aprobación de la Ley 19/82, sobre "Contratación de Productos Agrarios", inspirada en la norma francesa (op. cit. 10, pp. 150-151).

${ }^{26}$ En general, los esquemas contractuales utilizados alrededor del mundo son uniformes en sus aspectos centrales: prestación principal, partes intervinientes y modalidades de ejecución. Tal es así que mediante un trabajo conjunto de la FAO, UNIDROIT e IFAD, acaba de editarse recientemente una guía denominada Legal Guide for Contract Farming (2015) que, con cierta generalidad, destaca estos rasgos comunes. 
Mighell y Jones ${ }^{27}$ así como Eaton y Shepherd ${ }^{28}$ han observado en el campo general de la agricultura por contrato ${ }^{29}$ diferentes "intensidades de arreglos contractuales", las que se evidencian a partir de un conjunto de cláusulas tipo que se describen de la siguiente manera:

- Disposiciones (cláusulas) respecto de mercado: El agricultor y el comprador acuerdan los términos y condiciones para la compra y venta futura de un cultivo o producto agrario;

- Disposiciones (cláusulas) acerca de recursos: Junto con los arreglos de comercialización, el comprador acuerda suministrar insumos seleccionados, incluyendo, en ciertas ocasiones, la preparación de la tierra y la asistencia técnica;

- Disposiciones (cláusulas) concernientes a administración: El agricultor acuerda aplicar los métodos de producción recomendados, los regímenes de insumos, y las especificaciones de procedimiento de cultivo y cosecha y permite el control en el cumplimiento de tales requerimientos a lo largo del proceso productivo.

Mediante el empleo de estos tipos de cláusulas la agricultura por contrato comprende una variada gama de diseños contractuales, abarcando desde alternativas que se circunscriben a reglas básicas en el intercambio del producto por un precio (más asimilables al clásico contrato de compraventa), en un extremo, hasta aquellas en las que se determinan hasta los mínimos detalles del tracto de ejecución contractual, en el otro. A medida que los convenios entre productor y empresario se aproximen a este último modelo irán ingresando a la órbita de los denominados Contratos Agroindustriales.

Hamilton, uno de los autores que ha estudiado exhaustivamente el tema en Estados Unidos, lo caracteriza como

"un acuerdo a plazo fijo legalmente vinculante, perfeccionado antes de que comience la producción, en el que un productor se compromete a vender o entregar un cultivo específico, producido en hectáreas identificadas y designadas contractualmente, y realizado de acuerdo con especificaciones técnicas establecidas al contratista, por

${ }^{27}$ Mighell R. y Jones, citados en Minot N. W., Contract farming and its effect in small farmers in less developed countries, MSU International Development Papers, Working Paper No 31, Department of Agricultural Economics, Michigan State University, Michigan, 1986, pp. 13-14.

28 Eaton C. y Shepherd A. W., "La agricultura por Contrato. Alianzas para el crecimiento", en Boletín de Servicios Agrícolas de la FAO N $N^{0}$ 145. Organización de las Naciones Unidas para la Agricultura y la Alimentación, Roma, 2001, pp. 11-12. Disponible en: www.fao.org/docrep/004/y0937s/y0937s00.htm

${ }^{29} \mathrm{La}$ agricultura por contrato hace referencia -en términos generales- al uso de un contrato para pactar anticipadamente y programar la producción o la compra de determinada producción agrícola. Este término engloba desde la simple compraventa de cosecha futura, pasando por formas asociativas como las aparcerías o las modalidades genéricamente reconocidas como alianzas estratégicas, hasta las formas más cohesivas como lo son los contratos agroindustriales. Diversos autores han encarado el fenómeno de las nuevas modalidades de contratación de manera global y genérica, denominándolas así “agricultura por contrato", contract farming, en inglés (Pultrone y Da Silva (2014), Eaton y Shepherd (2001), Schejtman (1994), Minot (1986), Hamilton (1994 y 1995), entre otros). 
el que recibe el pago de un precio (fijo o calculado de acuerdo con un procedimiento establecido en el contrato), o bien es aquel acuerdo donde se compromete a alimentar y cuidar del ganado o de aves de corral propiedad del contratista hasta el momento en que los animales son retirados, a cambio de un pago en función del rendimiento de los animales. Según el acuerdo, el productor puede no tener la titularidad legal [de la propiedad] de la cosecha o el ganado, siendo un depositario, declarándose además como contratista independiente y no un empleado o empresa vinculada con el contratista" ${ }^{30}$.

Expresa Hamilton que este contrato crea una relación entre las partes que es única y diferente a las generadas por los contratos agrarios utilizados tradicionalmente, en los que no se incluyen cláusulas que facultan a controlar el proceso productivo (es decir, la ejecución de la prestación a cargo del productor agrario) ${ }^{31}$.

En forma concordante Kelley señala que

"frecuentemente el contratante [empresario procesador] es el que transforma el fruto agrario producido bajo este contrato en un producto de mayor valor agregado. Los contratos de producción permiten a este contratante controlar tanto la cantidad como la calidad de lo que ellos producen (...)"32.

Así como lo describe este autor, el contrato agroindustrial resulta para el empresario un modo eficaz de asegurarse la provisión regular de un insumo altamente específico en cuanto características organolépticas.

Entre los doctrinarios argentinos, Casella considera como contratos agroindustriales a aquellos acuerdos que buscan garantizar al industrial o comerciante la provisión de determinado producto de cierta calidad y en el tiempo convenido, pero resaltando también que de este modo el productor agrario se garantiza la colocación de su producción a precios de referencia, pudiendo contar con el adelanto de insumos, de recursos financieros y asistencia técnica. Asimismo, enfatiza que estos acuerdos acentúan los procesos de integración de los diversos sectores productivos, llegando incluso a desempeñarse el productor agrario en algunos casos como una mera empresa de servicios del procesador $^{33}$. Cuando ello sucede, reflexiona este autor, se verifica una pérdida casi absoluta del manejo de la propia empresa por parte del agricultor, quien se convierte en un mero ejecutor de órdenes del empresario comercial, aunque conserve todo el riesgo empresarial propio de la fase productiva.

Por nuestra parte, conceptualizamos al contrato de producción agroindustrial

“como aquel por el cual una parte (industrial, procesador, acopiador o comerciante) conviene con un agricultor o ganadero, cierta producción agrícola o cría de animales

\footnotetext{
${ }^{30}$ Hamilton, N., op. cit. 16, p. 2.

${ }^{31}$ Hamilton, N., op. cit. 16 , p. 2.

${ }^{32}$ Kelley, C., op. cit. 17, p. 2.

${ }^{33}$ Casella, A., op. cit. 4, p. 2.
} 
en un lugar específico (parcela de campo o establecimiento agrícola) detallando su cantidad y calidad, a cambio de una contraprestación que generalmente es un precio en dinero (que puede ser fijo o determinable por medio de sistemas preestablecidos contractualmente, incluyendo premios o castigos por los logros productivos). Asimismo, el industrial provee los insumos más importantes al productor (semillas o fertilizantes, el ganado para cría o engorde, etc.) en forma de adelanto y a cuenta de precio, y el cumplimiento del acuerdo frecuentemente es garantizado por el agricultor mediante algún título de crédito ejecutivo. El productor además está obligado contractualmente a respetar ciertas directivas técnicas de cría o manejo del cultivo, estableciéndose expresamente prerrogativas (facultades) de control del ciclo productivo a favor del empresario industrial" 34 .

Avanzando en el análisis de los rasgos distintivos de esta figura, corresponde resaltar que los sujetos intervinientes son siempre, por una parte, un agricultor o empresario $\operatorname{agrario}^{35}$ ("agricultor integrado"), y por la otra, un empresario procesador o industrial ("empresario integrador"). Estamos frente a un contrato de naturaleza intrínsecamente agraria, ya que el objeto del mismo es -esencialmente- el desarrollo del ciclo biológico, vegetal o animal ${ }^{36}$ que supone el proceso de cultivo o cría pactado en el contrato.

Asimismo, el contrato ya ha sido caracterizado en trabajos anteriores ${ }^{37}$ como de carácter bilateral, oneroso, de tracto sucesivo y duración. Se sostuvo también que como consecuencia de la existencia de obligaciones recíprocas e interdependientes (bilateralidad) que deben ser cumplidas en diferentes momentos temporales, surgen varias consecuencias legales reconocidas pacíficamente por la doctrina ${ }^{38}$, entre las que destacamos: la obligación del doble ejemplar, una parte no incurre en mora si la otra no cumple o no se allana a cumplir la obligación que le es anterior y correlativa, existiendo obligaciones recíprocas, una de las partes no puede demandar el cumplimiento si no prueba que ella cumplió u ofreció cumplir y la aplicación del pacto comisorio. Agregamos que el nuevo CCCN también permite aplicar a estos contratos institutos como el de la suspensión del cumplimiento y la frustración del fin, y todos los efectos propios de los contratos de duración, principalmente los relacionados con las rupturas intempestivas de relaciones regulares ${ }^{39}$.

${ }^{34}$ Ruiz, H., "Contratos de Producción Agroindustrial. Principales características y reflexiones en torno a su utilización”, en la Revista Actualidad y Prospectiva, de la Facultad de Ciencias Económicas de la UNNE, No 9, primavera 2012, pp. 105-106. Disponible en: http://eco.unne.edu.ar/revista/Edic_Ant.htm.. Último acceso: 15 de junio de 2015.

35 Sobre la categoría "empresario agrario" y "empresa agraria”, se recomienda Brebbia F. y Malanos N. (op. cit. 12, pp. 182-186) y Carroza A. y Zeledón Zeledón R., op. cit. 13.

${ }^{36}$ Carroza A., en Brebbia F. y Malanos N., op. cit. 12, pp. 79-80.

${ }^{37}$ Ruiz, H., op. cit. 36, p. 106.

${ }^{38}$ Lorenzetti, R. L., Tratado de los Contratos. Parte General, Rubinzal Culzoni Editores, Buenos Aires, 2004, pp. 211-212. En idéntico sentido, Gregorini Clusellas, E., Derecho de los Contratos. Tomo 1. Ed. Hammurabi, Buenos Aires, 2009, pp. 260-279.

39 "En principio, la facultad de rescindir en esas condiciones no supone un comportamiento reñido con la ley, pues no está vedado en el ordenamiento jurídico nacional, pero su ejercicio debe verificarse con 
Además, en razón de que nos encontramos frente a un contrato de tracto sucesivo, conviene destacar que la mayoría de las obligaciones que se crean son cronológicamente correlativas: cada obligación y cada derecho tiene un momento diferente y específico de cumplimiento o exigibilidad, dentro de un orden o sistema lógico. A modo de ejemplo, la obligación de suministrar los insumos por parte del empresario industrial es anterior al ejercicio de sus facultades de control, y a sus obligaciones de recepción de la cosecha y de pago. De ello se deriva que el cumplimiento tardío o deficiente de alguna de estas obligaciones podría alterar negativamente la cadena de ejecución de prestaciones, produciendo perjuicios irreparables para la consecución de los fines del contrato.

Respecto del objeto del contrato, la doctrina mantiene un debate inconcluso acerca de si el productor se obliga principalmente: i) a la producción de determinado fruto, ii) a la entrega (venta) en determinada fecha de ese fruto, o iii) a una variedad de prestaciones. En caso de adherir a la primera postura, colocando el foco en la actividad productiva, el contrato será considerado asimilable al de una locación -de obra o de servicios-. Para el supuesto de coincidir con la segunda alternativa, es decir, poniendo el eje en la operación de venta, concluiremos en que estamos en presencia de una compraventa de cosa futura. En caso de seguir la última postura, sostendremos el carácter sui generis de este contrato. Optar por una u otra postura reviste notables implicancias prácticas, toda vez que la aplicación o asimilación a una u otra calificación conlleva la aplicación de diferentes regímenes regulatorios.

Entendemos que la estructura y la dinámica del contrato agroindustrial exceden ampliamente a las de una simple compraventa futura. La existencia de múltiples obligaciones correlativas vinculadas al objeto principal pero que revisten cierta autonomía (caso del adelanto de insumos a cuenta de precio, o de la emisión de garantías por parte del productor), nos sugiere la importancia que tiene en la figura el tracto de ejecución contractual, vale decir, el desenvolvimiento del proceso productivo.

En efecto, este tejido obligacional constituye una nota distintiva del contrato, señalada también por Confortini y Zimatore en los siguientes términos:

"el contrato agroindustrial supone una relación en la que se combina 'una densa trama de obligaciones recíprocas', las que, además del efecto traslativo de la propiedad sobre los productos objeto del contrato, hace nacer múltiples obligaciones de hacer" ${ }^{\circledR 0}$.

En atención a ello, y siguiendo a destacados autores nacionales ${ }^{41}$, consideramos al contrato agroindustrial como de naturaleza sui generis.

prudencia, evitando una culminación sorpresiva e intempestiva que cause perjuicios patrimoniales a la otra parte. Si el ejercicio es abusivo se impone la obligación de reparar los daños causados por este comportamiento que viola el principio cardinal de buena fe". Freytes, A. E., "La rescisión unilateral y los contratos", en Revista de la Facultad de Derecho de la Universidad Nacional de Córdoba. Vol. 2 No 2, pp. 139-142. Asimismo actualmente el nuevo CCCN reconoce estos contratos y sus efectos especiales en el art. 1011.

${ }^{40}$ Confortini y Zimatore en Brebbia, F. y Malanos, N., op. cit. 12, p. 605.

${ }^{41}$ Brebbia, F. y Malanos N., op. cit. 12, p. 599. 
En él se pueden identificar una prestación principal declarada como objeto del contrato (la producción a cambio de un precio) y la existencia de un conjunto de prestaciones consistentes en obligaciones de hacer, no hacer y de dar, las que podrían ser llamadas secundarias, pero que claramente tienen carácter de "coadyuvantes" al cumplimiento de la obligación central.

En materia de distribución de los riesgos, se sostiene generalmente que corresponde a cada parte asumir el riesgo derivado del cumplimiento de su prestación, teniendo en cuenta que estamos ante contratantes que no se encuentran en un vínculo de dependencia ni asociativo, sino bajo una relación contractual de cambio. En este sentido es frecuente que los contratos incluyan cláusulas que subrayen esa independencia entre los establecimientos de los contratantes y establezcan expresamente la exención de responsabilidad de la empresa integradora por situaciones generadas en el establecimiento agrícola, aun por aquellas que ocurran a causa o en ocasión del cumplimiento del contrato agroindustrial

Finalmente, en cuanto a las ventajas atribuidas a esta modalidad contractual, a favor del agricultor se señalan: a) la posibilidad de una colocación segura de la producción a un precio acordado, b) la posibilidad de financiar la compra de insumos y en algunas ocasiones bienes de capital y c) la incorporación de tecnología, así como la disponibilidad de asesoramiento y seguimiento técnico. Por otro lado, la empresa procesadora consigue obtener similares beneficios a los de la integración en propiedad ${ }^{42}$, pero mejorando su capacidad de respuesta, adaptación y flexibilidad ante cambios de mercado ${ }^{43}$, y logrando reducir un importante número de costos fijos (como lo son el arrendamiento o compra de tierras para el desarrollo de la actividad productiva o la contratación de dependientes), y riesgos potenciales (aquellos intrínsecos a la activada agrícola, como el riesgo climático y el agronómico), ya que en estos contratos estos son soportados por su co-contratante.

\section{EL DAÑO AMBIENTAL INDIRECTO}

En materia ambiental tanto la doctrina como la jurisprudencia distinguen dos tipos de daños: el daño ecológico o directo y el daño de rebote o indirecto.

\footnotetext{
${ }^{42}$ El término se utiliza cuando una empresa o una unidad jurídica de decisión (por ejemplo un bolding o grupo de empresas) lleva a cabo -como titular-, además de su actividad principal u originaria, otra u otras actividades económicas que corresponden a eslabones productivos anteriores o posteriores. Ello se puede llevar a cabo adquiriendo en propiedad otras empresas en funcionamiento en dichos eslabones o generando una nueva empresa o departamento. La integradora se vuelve titular y propietaria, haciéndose responsable de todas las consecuencias jurídicas y económicas que sean producto de esas actividades. En el caso que estudiamos, permite a las empresas importantes ventajas competitivas que son garantizadas debidamente mediante la asunción directa de la fase productiva primaria (Sorvena (1989) en Teubal y Pastore, op. cit. 5, p. 111).

${ }^{43}$ En palabras de Teubal y Pastore (op. cit. 5, p. 118), estos contratos combinan una mayor flexibilidad y adaptación productiva a las fluctuaciones de demanda permitiendo incorporar productores mediante la firma de nuevos contratos y el manejo de los tiempos de abastecimiento, junto con una mayor capacidad de planificación global por parte del núcleo industrial.
} 
El primero, reconocido también como daño ambiental stricto sensu, es aquel que impacta directamente en la entidad ambiente y está constituido por cualquier tipo de degradación física, química o biológica relevante que lo afecte negativamente. Comprende el deterioro del entorno o hábitat, el menoscabo al paisaje, y el perjuicio al patrimonio cultural $^{44}$. En cambio, el daño de rebote o indirecto es el perjuicio al patrimonio o la salud de una o varias personas determinadas producido mediante disfuncionalidades ambientales ${ }^{45}$, en otras palabras, un "daño a la persona y sus bienes por alteración del ambiente" 46 .

Resalta Di Paola que el daño ambiental per se altera o destruye parcial o totalmente los ecosistemas y la calidad de vida de los seres vivos que lo componen, mientras que el daño a los individuos a través del ambiente comprende justamente al ambiente como medio para producir un menoscabo a las personas o sus bienes ${ }^{47}$. Sin embargo, es habitual que el daño directo y el indirecto se presenten de manera simultánea, lo que lleva a la doctrina a destacar el rasgo de bipolaridad o de doble cara como característico de la fisonomía del daño ambiental ${ }^{48}$.

Por este motivo Pizarro ${ }^{49}$, citando a Bustamante Alsina, señala que la de "daño ambiental" es una noción ambivalente, pues designa no solo al daño que recae en el ambiente como cosa común a toda una comunidad, sino también hace referencia al menoscabo que la lesión al medioambiente provoca, de rebote, respecto de los intereses legítimos de una persona determinada o de un grupo de personas determinado.

Así quedan diferenciadas las dos categorías de daños que la doctrina discierne en materia ambiental, los que si bien se pueden presentar juntas o separadamente, son distinguibles a partir de los bienes jurídicos tutelados en uno y otro caso: en el daño ambiental directo, el bien protegido es el ambiente autónomamente, como bien público, ya sea este el "macrobién ambiente o microbienes ambientales de dominio público" 50 , vinculados a derechos de carácter difuso o colectivo; mientras que en el daño indirecto el bien tutelado es la salud de la persona o de los bienes que integran su patrimonio, lo que da lugar a la existencia de derechos individuales.

${ }^{44}$ La Ley General del Ambiente (LGA) No 25.675 define el daño ambiental propiamente dicho en su artículo 27 como " $[\ldots .$.$] toda alteración relevante que modifique negativamente el ambiente, sus recursos, el$ equilibrio de los ecosistemas, o los bienes o valores colectivos" (Argentina, Ley N N $^{\circ}$.675, del 6 de noviembre de 2002, disponible en: http://www.infoleg.gob.ar/infolegInternet/anexos/75000-79999/79980/norma.htm )

${ }^{45}$ López Alfonsín, M., Derecho Ambiental, Editorial Astrea, Buenos Aires, 2012, pp. 244-245.

46 Walsh, J., y Preuss F., "El daño ambiental: La necesidad de nuevas instituciones jurídicas”, en Revista Jurisprudencia Argentina (JA: 1996-IV-962), citado en Cafferatta, N., "Los Daños al ambiente y su reparación”, en Daño Ambiental Revista de Derecho de Daños, 2008, No 3, Rubinzal Culzoni, Santa Fe, 2009.

47 Di Paola, M. E., "Daño ambiental”, comentario al artículo 41, en Sabsay D. (Dir.), Manili, P. (Coord.), Constitución de la Nación Argentina y normas complementarias. Análisis doctrinal y jurisprudencial, Tomo 2, Hammurabi, Buenos Aires, 2010, p. 221.

48 Cafferatta, N., "Los daños al ambiente y su reparación", en Daño Ambiental Revista de Derecho de Daños, 2008, No 3, Rubinzal Culzoni, Santa Fe, 2009, p. 171.

49 Pizarro, R. D., Tratado de Responsabilidad Objetiva, Thomson Reuters La Ley, Buenos Aires, 2015. Tomo II, cap. 32 apartado 256.

${ }^{50}$ Lorenzetti, R. L., "La protección jurídica del ambiente”, en Revista La Ley, E-1463, 1997. 
¿Resulta útil discernir entre estas categorías? La doctrina se pronuncia por la respuesta afirmativa ${ }^{51}$, ya que a partir de esta clasificación se determinará cuál es el régimen que regula cada tipo de daño y con ello se definirán cuestiones centrales como la legitimación activa, las facultades del juez, la naturaleza de la reparación, y si correspondiera, el destino de la indemnización pecuniaria.

En el caso del daño ambiental directo se deben aplicar el art. 41 de la Constitución Nacional, los Pactos Internacionales incorporados, el régimen de responsabilidad previsto en los arts. 27 a 33 de la Ley General del Ambiente (LGA), el bloque de normas federales conocidas como "Presupuestos Mínimos Ambientales" 52 , y las normas provinciales y municipales de la jurisdicción de su acaecimiento o posible concurrencia. A su vez, las normas aplicables para el caso de los daños de rebote son las de responsabilidad del derecho civil $^{53}$, que comúnmente se conocen con la denominación de "daños personales, patrimoniales o económicos" 54 . En el nuevo CCCN se sitúan en los arts. 1749 y siguientes, para los casos de responsabilidad directa, y en los arts. 1757 y siguientes, para los de responsabilidad derivada de actividades riesgosas. Es factible resaltar, en virtud de que en este caso particular el daño se genera por medio del ambiente, que la aplicación de las normas civiles señaladas debe realizarse siempre en sintonía con lo dispuesto en el art. 41 de la CN y la LGA 55 .

En cuanto a la legitimación activa, en materia de daño ambiental de incidencia colectiva es aplicable el art. 30 de la LGA, mientras que en el daño ambiental individual rigen los principios ordinarios del Código Civil y Comercial, según el menoscabo sea patrimonial o moral ${ }^{56}$.

Por último, la responsabilidad derivada del daño ambiental colectivo posee prioritariamente una función recompositiva ${ }^{57}$ y solo de manera accesoria o subsidiaria procede

51 Pizarro, R. D, op. cit. 51; Di Paola, M. y Sabsay, D., "El daño ambiental colectivo y la nueva ley general del ambiente", en Revista La Ley, 2003-D, 4865, cita online: AR/DOC/130/2000; Novak, A., "Una cosa es una cosa y otra cosa es otra cosa. De daños ambientales individuales y colectivos", en Revista La Ley Córdoba, 2015 (agosto), 736, cita online: AR/DOC/707/2015.

52 Compuesto por las Leyes Nacionales No 24.051 de "Residuos Peligrosos", No 25.612 de "Gestión Integral de Residuos Industriales y de Actividades de Servicios,", No 25.670 de "Gestión y Eliminación de PCB”, No25.688 de "Gestión Ambiental de Aguas", No 25.831 de "Libre acceso a la Información Pública", $\mathrm{N}^{\circ} 25.916$ de "Presupuestos Mínimos para la Gestión de Residuos Domiciliarios", N 26.331 de "Protección Ambiental de Bosques Nativos", N²6.562 de "Actividades de quema en todo el Territorio Nacional”, y No 26.639 de "Preservación de los Glaciares y del Ambiente Periglacial".

${ }^{53}$ Di Paola, op. cit. 49, p. 221.

${ }^{54}$ López Alfonsín, M., op. cit. 47, p. 247.

${ }^{55}$ Para profundizar en la materia, véanse Sagarna, F., "Responsabilidad civil directa y por el hecho de terceros en el nuevo Código Civil y Comercial de la Nación”, en Sup. Esp. Nuevo Código Civil y Comercial, Revista La Ley (17/11/2014); Pizarro, R. D. "Responsabilidad civil por actividades riesgosas o peligrosas en el nuevo Código" (2015-D), en Revista La Ley (12/08/2015); Galdós, J. M., "Riesgo creado y actividad riesgosa en el Proyecto 2012 de Código Civil y Comercial de la Nación”, en Revista Derecho de Daños, La Ley N 3, 2012.

56 Pizarro, R. D., op. cit. 51.

${ }^{57}$ Es importante destacar que la función prioritaria de recomponer el daño ambiental colectivo tiene origen directo y expreso en la CN: "El daño ambiental generará prioritariamente la obligación de recomponer, según lo establezca la ley” (art. 41 1er. párrafo ultima parte). 
la indemnización pecuniaria, la que se destina al Fondo de Compensación Ambiental que crea la LGA (art. 34). Tratándose de daño ambiental individual, la naturaleza de la responsabilidad es principalmente resarcitoria y el monto indemnizatorio se destina a cada damnificado, en la medida del daño efectivamente sufrido. Se destaca que respecto de la función preventiva de la responsabilidad ambos sistemas se han asimilado notablemente a partir de la sanción del nuevo CCCN (arts. 1708, 1710 a 1713 CCCN) ${ }^{58}$.

En lo que a los objetivos de este trabajo concierne, es de suma importancia delimitar el verdadero sentido y alcance de las normas que regulan el supuesto daño ambiental indirecto derivado de actividades riesgosas o peligrosas, por lo que resulta indispensable previamente especificar cuáles son los criterios interpretativos promovidos por la legislación sancionada recientemente $(\mathrm{CCCN})$, los que ayudarán a identificar la normativa aplicable para la resolución de la cuestión planteada.

\section{FUENTES DE LA RESPONSABILIDAD POR DAÑO AMBIENTAL INDIRECTO DERIVADO DE ACTIVIDADES RIESGOSAS. SUS POSIBLES INTERPRETACIONES}

El art. 1758 in fine CCCN dispone que debe responder por los daños ocasionados por actividades riesgosas "quien la realiza, se sirve u obtiene provecho de ella, por sí o por terceros, excepto lo dispuesto por la legislación especial" 59.

En la interpretación tradicional de esta norma diversos autores distinguen la existencia de hasta dos posibles sujetos pasivos del deber de responder: 1) la persona que realiza la actividad riesgosa; 2) la persona que se sirve u obtiene provecho de la actividad riesgosa; en lo que podría denominarse, con cierta escasez creativa, "teoría bipartita de sujetos pasivos" 60 .

Pizarro explica que

"realiza la actividad riesgosa quien de manera autónoma lleva a cabo o ejecuta la actividad riesgosa, por sí o por terceros. Se sirve u obtiene provecho de la actividad riesgosa quien satisface a través de la misma un interés patrimonial o extrapatrimonial. A menudo quien realiza la actividad riesgosa es quien se sirve u obtiene un

${ }^{58}$ La reforma del año 1994 de la CN y la LGA del año 2002 reconocen los principios Preventivo y Precautorio en materia ambiental de incidencia colectiva. En cambio, la función preventiva del derecho de daños es más reciente en el ámbito civil, siendo consagrada legislativamente con la sanción del CCCN a fines del 2014.

${ }^{59} \mathrm{El}$ art. $1757 \mathrm{CCCN}$ establece que las actividades pueden ser riesgosas o peligrosas por su naturaleza, por los medios empleados o por las circunstancias de su realización. Las discusiones en torno al concepto, clases o modalidades y extensión de las actividades riesgosas o peligrosas exceden los límites del presente artículo. Al respecto sugerimos consultar las posturas de Pizarro, R. D., "Responsabilidad civil por actividades riesgosas o peligrosas en el nuevo Código”, en La Ley, 12/08/2015, y Galdos, J. M., op. cit. 57.

${ }^{60}$ Estas lecturas concuerdan con las realizadas respecto del art. 1113 C.Civ. (antecedente del art. 1758 $\mathrm{CCCN}$ ), en las que generalmente se señalaban los mismos posibles legitimados pasivos. 
provecho de ella. Pero puede ello no ser así y aparecer ambas calidades disociadas. En tal caso, ambos responden" 61 .

En concordancia, y poniendo el énfasis en la inmutabilidad de la regla posrefoma del Código, Compagnucci de Caso sostiene que

“en el supuesto del 'riesgo de actividad', los responsables son el operador o quien la realiza, y el que se sirve y obtiene provecho de dicha actividad [...] no hay incorporación de noveles responsables, sino que se mantiene la característica de ser el 'guardián' el que debe asumir la carga de estar obligado, ya que será consecuencia de la guarda material, jurídica o de provecho la que dará causa suficiente a ello" 62 .

Para Galdós, quien también adhiere a la teoría bipartita, junto con la figura del realizador de la actividad riesgosa, se sitúa como obligado la persona que se sirve u obtiene provecho generalmente económico de dicha actividad, y siempre cuando este último tenga facultades de organización o de control sobre las tareas peligrosas ${ }^{63}$.

Sin embargo, también entendemos posible afirmar que:

$\left.1^{\circ}\right)$ El art. 1758 in fine comprende en realidad la descripción de tres supuestos de responsabilidad, y no solamente de dos -como señalan los autores mencionados-, posición que en función de la clasificación que venimos utilizando será denominada teoría tripartita. Además de quien realiza la actividad, pueden ubicarse como personas distintas: quien se sirve de la misma, por un lado, y quien obtiene provecho de ella, por otro. Esto importa distinguir y admitir la separabilidad de dos conceptos o situaciones posibles: la de servirse de una actividad y la de sacar provecho de una actividad ${ }^{64}$.

$2^{\circ}$ ) La noción de "servirse" como equivalente a satisfacer un interés patrimonial o extrapatrimonial provista por cierto sector de la doctrina constituye una representación de tal amplitud que termina dificultando severamente su aplicación efectiva. Por ello deviene necesario delimitar con mayor precisión los contornos del concepto.

La expresión "servirse de" es empleada en diversos artículos del CCCN, aclarando que siempre aparece vinculada a una cosa (y no a una actividad, como sucede en la hipótesis

61 Pizarro, R. D., op. cit. 60, p. 4.

${ }^{62}$ Compagnucci de Caso, R., en Bueres, A. (dir.), Código Civil y Comercial de la Nación analizado, comparado y concordado, 1 ra. ed., Hammurabi, Buenos Aires, 2014, vol. 2, p. 186 (el destacado es propio).

63 Galdós, J. M., op. cit. 57.

${ }^{64}$ Hemos desarrollado esta postura en: Gapel Redcozub, G. y Ruiz, H. E. "Usufructo y daños: responsabilidad del nudo propietario por daño ambiental indirecto derivado de actividades riesgosas del usufructuario", Ponencia presentada en la Comisión de Derecho Reales de las XXV Jornadas Nacionales de Derecho Civil, desarrolladas en Bahía Blanca en el 2015 a la que nos remitimos. Disponible en: http:// jndcbahiablanca2015.com/?cat=30\&comision=1831. Último Acceso: 20 de febrero de 2016. 
bajo análisis). En los arts. 1367 (depósito irregular), 1536 y 1538 (obligaciones del comodatario), 2180 (derechos del titular del fundo sirviente), 2018 y 2020 (medianería), "servirse" importa valerse de la cosa según el uso que es propio de ella, y requiere tener el control o la ocupación de la cosa. Así, servirse de una actividad riesgosa equivaldría a obtener la finalidad material directa de la actividad, hacerse con su efecto inmediato, contando con facultades de dirección o control de estas tareas.

A diferencia de la postura sostenida por Galdós, en la que "servirse" incluye necesariamente el elemento de provecho económico o de otra naturaleza ${ }^{65}$, en la concepción que proponemos la idea de beneficio es accesoria, y su ausencia no es relevante para determinar la existencia de un sujeto "servido".

Desde este punto de vista, "servido" es quien se hace con la materialidad del producido de la actividad riesgosa, ya sea que la realice per se o que delegue su ejecución en un tercero ("servidor-realizador"), conservando significativas facultades de dirección y control. Es probable que el servido derive beneficios económicos de dicha materialidad o producido, es decir, sea también el principal "aprovechador" de la actividad, pero esta característica no resulta constitutiva del concepto de "servirse".

Bajo el esquema señalado, entonces, los sujetos responsables por la actividad riesgosa o peligrosa (AR) del art. 1758 in fine pueden ser:

El "REALIZADOR"

El "SERVIDO”

\section{El "APROVECHADOR" o "BENEFICIARIO"66}

Lleva adelante la AR en forma personal o mediante un dependiente (trabajador), para sí mismo o para un tercero contratante (siendo en este último caso un "servidor").

$E j$. Productor que aplica un plaguicida en su propia explotación; titular de empresa de servicios agrícolas que es contratado para aplicar un plaguicida en la explotación de un tercero.
Obtiene las ventajas materiales generadas por la AR que realiza per se o cuya ejecución delega en un contratado o subcontratado ("servidor"), conservando significativas facultades de dirección y control.

$E j$. Empresa industrial que celebra un contrato agroindustrial con un productor primario, en virtud de ello este último realizará en su propia explotación un proceso que conlleva AR, y que será dirigido/controlado por el industrial, a quien le entregará finalmente la producción a cambio del pago de un precio.
Obtiene las ventajas económicas derivadas de las consecuencias materiales de la AR.

Puede coincidir o no con la persona del Servido o del Realizador. Ej. Un nudo propietario o locador cuyos ingresos se pactan con el usufructuario o locatario en función del rendimiento obtenido en un proceso productivo que incluye AR.

Aunque no tenga injerencia en la producción, percibirá mayores beneficios pecuniarios si la AR mejora los resultados materiales de la explotación.

${ }^{65}$ Esto posiblemente ocurre porque Galdós adhiere a la teoría bipartita (en Galdós, J. M., op. cit. 57), en la que "servirse" funciona de manera indisociable con "obtener provecho".

${ }^{66}$ Esta hipótesis fue tratada en mayor extensión en Gapel Redcozub, G. y Ruiz, H. E., op. cit. 66. 
Puede suceder que una misma persona ejecute la AR (realizador), haciéndose con los efectos inmediatos o materiales de dichas tareas (servido) y también con el provecho económico derivado de estas consecuencias materiales (aprovechador), convergiendo de este modo los tres supuestos de responsabilidad en un único sujeto.

Sin embargo, también es perfectamente posible que se produzca un desdoblamiento de roles, en donde el realizador y el servido ocupen lugares distintos de la cadena productiva.

Esto es exactamente lo que sucede en los contratos agroindustriales que demandan el desarrollo de actividades riesgosas o peligrosas, en los que el empresario integrador contrata con el productor agrario, entregándole los insumos, imponiéndole estrictas directivas de producción, otorgándole asistencia técnica o financiera, reservándose facultades de control y asegurándose la adquisición del producido.

En este escenario, el empresario integrador es un indiscutible "servido" por la actividad riesgosa llevada a cabo por el productor agrario, y queda subsumido en la normativa indicada con independencia del provecho económico que pueda derivar de la situación. Es decir, no deviene necesario efectuar ningún análisis de costo-beneficio o de determinación de ventajas puntuales a favor del empresario integrador para proceder a su calificación.

Por supuesto, la calidad de servido puede ser coincidente con la de aprovechador, lo que sucederá cuando quien se hace con la materialidad del producido de la actividad riesgosa obtenga también beneficios económicos de la misma fuente. Por ejemplo, cuando los granos o las aves que recibe de manos del productor agrario, cultivados o criados mediante el empleo de actividades peligrosas, dirigidas y controladas por el empresario integrador, le reporten a este último una utilidad económica mayor o extraordinaria.

Cuando ello ocurre, y es de esperar que así sea en la mayoría de los casos, debe responder en su doble calidad, es decir, como servido y como aprovechador de la actividad riesgosa.

Frente a la lectura clásica de legitimación pasiva (bipartita) del art. 1758 in fine, surge entonces, basado en los fundamentos expuestos, la cuestión de la posible extensión de la responsabilidad al servido por la actividad riesgosa, derive o no provecho económico de ella, es decir, con independencia de su calidad de aprovechador (postura tripartita).

La propuesta del artículo es indagar si a partir de los nuevos parámetros de interpretación del CCCN corresponde formular una relectura de dicha norma imputativa de responsabilidad civil, dando cabida a este supuesto específico de legitimación pasiva por daños ambientales indirectos derivados de actividades riesgosas.

\section{PAutas PARA LA IDENTIFICACIÓN Y SELECCIÓN DEL CRITERIO INTERPRETATIVO ADECUADO AL CASO}

El art. 2 del CCCN establece expresamente la necesidad de que en la interpretación del derecho converjan el texto expreso de la norma, junto con su finalidad, las leyes análogas, los tratados acerca de derechos humanos y los principios y valores jurídicos, "de modo coherente con todo el ordenamiento". 
En palabras de la doctrina,

“el Código Civil y Comercial [...] pretende ser el factor de integración del conjunto de los microsistemas del derecho privado. Dicho de otro modo, las fuentes dialogan: las leyes especiales, los microsistemas, no existen en el aislamiento, en el vacío, sin interrelación alguna; al contrario, sin perjuicio de sus reglas específicas, pueden acudir al [Código Civil y Comercial] como instrumento de integración al sistema” 67 .

El artículo citado consagra el mandato de perseguir una integración armónica del sistema jurídico, teniendo en consideración en todo momento las normas de jerarquía superior y las leyes especiales. Esta búsqueda exige repensar de manera permanente los derechos y obligaciones de los sujetos, los que irán cambiando inexorablemente a medida que se introduzcan innovaciones al ordenamiento vía incorporación de tratados, leyes especiales o solo por medio de la reinterpretación de estas fuentes, y a medida que las nuevas realidades tornen obsoletas las viejas interpretaciones ${ }^{68}$.

Por ello, a los fines de responder el interrogante acerca de la eventual responsabilidad ambiental de las partes en un contrato agroindustrial deviene necesario formular una relectura de los derechos y obligaciones de los sujetos intervinientes, y, especialmente, de sus deberes en materia ambiental.

En el marco del nuevo paradigma vigente, entonces, analizaremos si la interpretación de "servido" señalada como posible se ajusta a los términos de la normativa especial, y sobre todo, si es superadora de la versión tradicional en el sentido de que se integra y complementa más adecuadamente con el ordenamiento como un todo.

En esta dirección, la LGA, que es la ley especial en materia ambiental, enumera como uno de los instrumentos de política ambiental al "sistema de control sobre el desarrollo de actividades antrópicas" (art. 8 inc. 3). De esto se deduce que las regulaciones que imponen deberes de tutela ambiental y asignan responsabilidades en caso de producción de daños forman parte del sistema de control sobre actividades antrópicas y, por tanto, deben ser reputadas como instrumentos de política ambiental. En consecuencia, resulta acertado calificar al art. 1758 C.Civ. in fine como una norma que integra o que debe funcionar en sintonía con la política ambiental nacional, en tanto norma que asigna

${ }^{67}$ Kemelmajer de Carlucci, A., Código Civil y Comercial Comentado, Infojus, CABA, 2015, Tomo I, pp. XV y XVI. Según esta autora la doctrina debe ser el principal instrumento para llevar adelante el diálogo de fuentes.

68 “El Código Civil y Comercial de la Nación inaugura su Título Preliminar refiriendo a los 'casos' que este Código rige. Un 'caso', como tal, no se entiende como un suceso histórico en su dimensión puramente fáctica; por el contrario, para el Derecho se trata, esencialmente, de un acontecimiento problemático que plantea la cuestión -muchas veces ardua- acerca de cómo responder a él en términos jurídicos. Las dificultades en la resolución de algunos de estos 'casos' ( hard cases) en una sociedad cada vez más compleja exigen generar continuas reconstrucciones interpretativas del ordenamiento vigente”. Kemelmajer de Carlucci, A., Fernández, S. y Herrera, M., "Bases para una relectura de la restricción a la capacidad civil en el nuevo Código", La Ley, 18/08/15, p. 1, el destacado es propio). 
responsabilidades en caso de la producción de daños, en este particular caso derivados del ambiente, o más precisamente, de la contaminación al ambiente.

Asimismo, la misma ley en su art. 4 establece que la interpretación de toda norma en la que se ejecute la política ambiental queda sujeta al cumplimiento de ciertos principios, entre los que se encuentra el principio de prevención que es tomado directamente de la Constitución Nacional.

Explica la doctrina que

\begin{abstract}
"la Constitución Nacional, consagra en el artículo 41, el derecho al ambiente sano, equilibrado, apto para el desarrollo humano [...], y el desarrollo sustentable. Pero también establece el 'deber de preservarlo', lo que se condice con los principios de política ambiental, de prevención y precaución, contenidos en los artículos $4^{\circ}$ y $5^{\circ}$ de la Ley 25675 General del Ambiente. Dichos principios obligan al operador jurídico -el juez, la autoridad competente o de aplicación de la normativa ambiental-, metodológicamente, a priorizar el análisis, en la etapa previa al daño (predaño), operando sobre las causas y las fuentes de los problemas ambientales, tratando de impedir la consumación del daño ambiental"69.
\end{abstract}

Este precepto constitucional, plasmado en el principio de prevención del art. 4 de la LGA, debe necesariamente ser tenido en cuenta al interpretar normativas del CCCN que posean injerencia clara o que directamente formen parte de la política ambiental. Este principio no debe ser entendido como una mera expresión de deseos sino como una poderosa herramienta hermenéutica. En palabras de López Alfonsín:

"los principios jurídicos ambientales son operativos, y tienen un efecto jurídico reestructurante del sistema normativo argentino [...] Así resultan de vital importancia tanto para evitar el avance disfuncional de la normativa correspondiente a otra temática, como también coadyuvan a alcanzar el desarrollo y consolidación de la reglamentación propia, delimitando, de esa manera, las fronteras de la especialidad"70.

Y adicionalmente, vale remarcar que la lectura efectuada de la ley especial se complementa armónicamente y se refuerza con la nueva función preventiva del sistema de responsabilidad general adoptado por el CCCN en los arts. 1710 y siguientes ${ }^{71}$.

${ }^{69}$ Cafferatta, N., "Derecho ambiental en el Código Civil y Comercial de la Nación”, en La Ley Suplemento Especial Nuevo Código Civil y Comercial 2014, noviembre, 17/11/2014, p. 10.

${ }^{70}$ López Alfonsín, M., op. cit. 47, pp. 203-204.

71 "El ingreso del principio de prevención al Código Civil y Comercial, fortalece la postura de defensa del ambiente. Aunque hace tiempo se sabe en la doctrina que el Derecho de Daños incluye además de la resarcitoria o indemnizatoria, una función preventiva y disuasiva, es valioso que expresamente se establezca esta regla de funcionalidad del instituto de la responsabilidad civil, en todas sus variantes" (Cafferatta, N., ob. cit. 71, p. 13). En sentido concordante puede verse Lorenzetti, P., "Funciones de la responsabilidad civil y daño ambiental en el Proyecto de Código Civil y Comercial de la Nación de 2012”, RCyS, 2013-VIII, 5, cita online: AR/DOC/2574/2013. 
Reflexionando, entonces, acerca de la manera de interpretar el conjunto de posibles sujetos responsables señalados por el art. 1758 in fine que mejor se adecue al principio de prevención del daño ambiental y a la función preventiva del nuevo sistema de responsabilidad del CCCN, parece atinado postular que la versión de "servido" aquí empleada es superadora de la tradicional, en la que, recordemos, el concepto es tan laxo que resulta inaplicable, o bien va asociado indisolublemente a la obtención de un provecho, circunstancia que podría reputarse como innecesaria.

La aseveración se fundamenta en que el sentido y el alcance propuesto para la figura del "servido" posibilita una mejora incremental en el esquema de responsabilidad por daños ambientales indirectos, presentando ventajas en diferentes órdenes:

$1^{\circ}$ ) Genera incentivos para que una persona adicional (en el caso bajo análisis, el empresario integrador) ejerza sus facultades de dirección y control de manera responsable en relación con las eventuales consecuencias ambientales que las actividades riesgosas o peligrosas puedan tener, aumentando así las chances de prevención de daños ambientales directos e indirectos ${ }^{72}$. Huelga decir que este responsable adicional no es un sujeto cualquiera, sino quien desempeña un rol destacado en la organización del proceso en cuyo seno se lleva a cabo la actividad riesgosa, de manera que se encuentra en una posición inmejorable para evitar el acaecimiento de daños. Estos incentivos están perfectamente alineados con el deber de preservación del ambiente previsto en el art. 41 de la $\mathrm{CN}$ para todos los ciudadanos, y con el principio de prevención del daño consagrado en el art. $4^{\circ}$ de la LGA.

$2^{\circ}$ ) Simplifica razonablemente el análisis de la imputación de responsabilidad, eliminando la necesidad de indagar acerca de la existencia o no de provecho económico o de cualquier otra naturaleza en el caso concreto -bastará con acreditar la condición de servido, en los términos expuestos anteriormente, para determinar la procedencia del deber de reparación-. Así se reducen los costos y la duración de los procesos judiciales indemnizatorios, lo que redundará en un ostensible beneficio para las víctimas. Esta es una de las directrices proclamadas por la Declaración de Rio sobre el Medio Ambiente y el Desarrollo (1992), en la que se abogó por el acceso efectivo a los juicios por resarcimiento de daños que tienen en su génesis cuestiones ambientales como mecanismo de protección individual y colectivo $^{73}$.

72 También se incrementan las chances de reparación o recomposición en el supuesto de que el daño se verifique, al agregar un patrimonio adicional y presumiblemente solvente en el que se podrá perseguir el cobro de las indemnizaciones debidas.

${ }^{73}$ Informe de la Conferencia de las Naciones Unidas Sobre el Medio Ambiente y el Desarrollo (Rio de Janeiro, 3 a 14 de junio de 1992). Anexo I. PRINCIPIO 10: "El mejor modo de tratar las cuestiones ambientales es con la participación de todos los ciudadanos interesados, en el nivel que corresponda. En el plano nacional, toda persona deberá tener acceso adecuado a la información sobre el medio ambiente de que dispongan las autoridades públicas, incluida la información sobre los materiales y las actividades que encierran peligro en sus comunidades, así como la oportunidad de participar en los procesos de adopción de decisiones. Los Estados deberán facilitar y fomentar la sensibilización y la participación de la población poniendo la información a disposición de todos. Deberá proporcionarse acceso efectivo a los 
$3^{\circ}$ ) Asimismo, desde el punto de vista axiológico, el esquema sugerido puede considerarse valioso toda vez que evita la situación injusta que se genera cuando la responsabilidad por daño ambiental indirecto se limita al sujeto que si bien ejecutó la acción dañosa, lo hizo en cumplimiento de las órdenes o directivas impartidas por el empresario, o cuanto menos bajo su supervisión, aunque no exista relación de dependencia laboral o control societario. En este sentido, la interpretación propuesta carga también sobre el empresario integrador los eventuales costos ambientales de las actividades riesgosas que dirige y controla (y de las que habitualmente obtiene beneficios económicos, en cuyo caso será también un aprovechador).

En definitiva, según los parámetros de esta interpretación de la responsabilidad por actividades peligrosas del art. 1758 in fine, el empresario integrador deberá interesarse no solo en la dirección y control del proceso productivo en miras de maximizar la obtención de frutos o de optimizar resultados endógenos, sino que estará obligado a considerar las consecuencias de las actividades que coordina bajo pena de internalizar los costos por los daños ambientales indirectos que sus contratados y dirigidos puedan ocasionar al ejecutar este tipo de actividades. Más aún, en el caso será de aplicación un factor de atribución objetivo, en el que la culpa resulta irrelevante y para liberarse deberá acreditar la existencia de causa ajena, la que, vale aclarar, nunca podrá residir en la conducta del productor integrado ${ }^{74}$.

Finalmente, es importante señalar que existen en Argentina algunos precedentes judiciales en los que se impuso el deber de indemnizar al sujeto que cumple una función similar a la de quien aquí hemos caracterizado como servido ${ }^{75}$. Aunque confinados por los límites de una normativa que había quedado un tanto desactualizada ${ }^{76}$, este tipo de decisiones han sido pioneras en reconocer en ciertos casos la procedencia de la extensión de responsabilidad por actividades riesgosas a los sujetos que organizan, dirigen y controlan los procesos en cuyo marco estas actividades se despliegan. Lamentablemente no puede afirmarse aún que estos fallos hayan alcanzado el rango de jurisprudencia mayoritaria, ni que se hayan diseminado profusamente a lo largo de los distintos tribunales del país.

En la actualidad, la consolidación de un nuevo bloque de legalidad abre la posibilidad de edificar sobre estos cimientos, precisando e integrando los conceptos, explicitando los vínculos entre instituciones y armonizando el funcionamiento conjunto de los diversos dispositivos normativos, siempre con la finalidad de contribuir al desarrollo de

procedimientos judiciales y administrativos, entre estos el resarcimiento de daños y los recursos pertinentes". Disponible en http://www.un.org/spanish/esa/sustdev/agenda21/riodeclaration.htm Último Acceso: 20 de marzo de 2016.

${ }^{74}$ Art.1722 CCCN.- Factor objetivo. "El factor de atribución es objetivo cuando la culpa del agente es irrelevante a los efectos de atribuir responsabilidad. En tales casos, el responsable se libera demostrando la causa ajena, excepto disposición legal en contrario".

${ }^{75}$ Fallo "Bogado, Juan Jorge y otro c/ Toledo, Víctor y otros s/ daños y perjuicios”, Suprema Corte de la Provincia de Buenos Aires, 15/07/2015.

${ }^{76}$ El art. 1113 del Código Civil derogado utilizado para fundar estas sentencias no contemplaba expresamente la responsabilidad por "actividades riesgosas", concepto que fue delineado paulatina y trabajosamente por parte de la doctrina y jurisprudencia. 
un sistema de responsabilidad ambiental más acorde con los valores, los desafíos y las realidades de la época.

\section{CONCLUSIONES}

Los contratos agroindustriales se han propagado velozmente en los últimos años como instrumentos de coordinación y control de la producción primaria destinada a industrialización, convirtiéndose en piezas claves para el funcionamiento de ciertos subsectores económicos. De manera simultánea se percibe un crecimiento notable de conflictos ambientales que comprenden casos graves de daños sufridos por personas, animales y el ambiente, en el marco del desarrollo de estos esquemas productivos.

Debido a que uno de los rasgos más característicos y novedosos de los contratos agroindustriales utilizados en estos esquemas es el traslado de las facultades de dirección y control sobre el proceso productivo primario desde el agricultor hacia el empresario integrador (o industrial), nos propusimos repensar la situación en que se encuentra este último cuando el primero ocasiona daños ambientales indirectos como consecuencia de la ejecución de actividades riesgosas.

Siguiendo los criterios provistos por el nuevo bloque de legalidad, reinterpretamos el sistema tradicional de responsabilidad civil basado en el art. 1758 in fine CCCN, concluyendo que resulta posible extender la responsabilidad al sujeto servido por la actividad riesgosa, derive o no provecho económico de ella, es decir, con independencia de su calidad de aprovechador de la misma.

Por los fundamentos expuestos, entendemos que la lectura propuesta de la norma se adecua mejor al principio constitucional de prevención del daño ambiental y a la función preventiva asignada al régimen de responsabilidad del CCCN, siendo por ella superadora de la versión clásica o tradicional.

Asimismo, desde el punto de vista axiológico, la interpretación sugerida puede considerarse valiosa toda vez que evita la situación injusta que se genera cuando la responsabilidad por daño ambiental indirecto se limita al sujeto que si bien ejecutó la acción dañosa, lo hizo en cumplimiento de las órdenes o directivas impartidas por el empresario, o cuanto menos bajo su supervisión, aunque no exista relación de dependencia laboral o control societario.

\section{BIBLIOGRAFÍA}

BIVONA, G., I contratti d'integrazione verticale in agricoltura, Giuffrè Editore, Milano, 1979, pp. 2-4. Brebbia, F. y Malanos, N., Derecho Agrario, 2 Reimpresión, Editorial Astrea, Buenos Aires, 2011. Cafferatta, N., "Los Daños al ambiente y su reparación”, en Daño Ambiental Revista de Derecho de Daños, 2008, N 3, Rubinzal Culzoni, Santa Fe, 2009.

Cafferatta, N., "Derecho ambiental en el Código Civil y Comercial de la Nación”, en La Ley Suplemento Especial Nuevo Código Civil y Comercial 2014, noviembre, 17/11/2014, p. 10.

Carroza, A. y Zeledón Zeledón, R., Teoría General e Institutos del Derecho Agrario, Editorial Astrea, Buenos Aires, 1990, pp. 309-330. 
Casella, A. P., Modalidades Negociales de la Empresa Agraria en el Marco del Complejo Agroindustrial y Agroalimentario: Contratos Agroindustriales y Acuerdos Interprofesionales. Comunicaciones Científicas y Tecnológicas de la UNNE, Universidad Nacional del Nordeste, Corrientes, 2001, pp. 1-2.

Compagnucci de Caso, R., en Bueres, A. (dir.), Código Civil y Comercial de la Nación analizado, comparado y concordado, 1 ra. ed., Hammurabi, Buenos Aires, 2014, vol. 2, p. 186.

Da Silva, J. G., "Complejos Agroindustriales y Otros Complejos”, en Revista Brasileña Reforma Agraria, $\mathrm{N}^{\circ} 3$ Vol. 21, septiembre-diciembre de 1991, pp. 205-206.

Di Paola, M. E., "Daño Ambiental”, comentario al artículo 41, en Sabsay D. (Dir.), Manili P. (Coord.), Constitución de la Nación Argentina y normas complementarias. Análisis doctrinal y jurisprudencial, Tomo 2, Hammurabi, Buenos Aires, 2010.

Di Paola, M. y Sabsay, D., "El daño ambiental colectivo y la nueva ley general del ambiente”, en Revista La Ley, 2003-D, 4865, cita online: AR/DOC/130/2000.

Domènech, G., Los Contratos de Integración Agroindustrial, Ediciones Cooperativas, Buenos Aires, 2010, pp. 103-136.

EAтоn C. y Shepherd A. W., "La agricultura por Contrato. Alianzas para el crecimiento", en Boletín de Servicios Agrícolas de la FAO N $N^{0}$ 145. Organización de las Naciones Unidas para la Agricultura y la Alimentación, Roma, 2001, pp. 11-12.

Formento, S. Empresa Agraria y sus Contratos de negocios, Editorial Facultad de Agronomía, Universidad de Buenos Aires, Buenos Aires, 2005, pp. 139-163.

Formento, S. y Pilatti, H., "Los Contratos Agroindustriales: su perfil jurídico”. Ponencia presentada en el VII Congreso de Derecho Agrario Argentino, Octubre 2004, Bahía Blanca.

Gapel Redcozub, G. y Ruiz, H. E. "Usufructo y daños: responsabilidad del nudo propietario por daño ambiental indirecto derivado de actividades riesgosas del usufructuario”, Ponencia presentada en la Comisión de Derecho Reales de las XXV Jornadas Nacionales de Derecho Civil, Bahía Blanca, 2015.

Germanò, A. "Sul contratto di cessione di prodotti Agricole e Alimentari”, en Rivista Diritto e Giurisprudenza Agraria, Alimentare e dell ambiente, No 6, junio 2012, pp. 379-396.

Gregorini Clusellas, E., Derecho de los Contratos. Tomo 1. Ed. Hammurabi, Buenos Aires, 2009, pp. 260-279.

Hamilton, N., Farmer's Legal Guide to Production Contracts, Research Project, The National Agricultural Center. University of Arkansas. School of Law-Division of Agriculture, Arkansas, 1995.

IANNARELLI, A. "Le relazioni contrattuali tra agricoltura e idnsutria nella recente esperienza giuridica italiana”, en Massart, A. (dir.), Accordi Interprofesionali e contratti agroindustriali, ETS Editrice, Pisa, 1990, pp. 70-89.

Kassıa, W., "Relações Contratuais no Agribussiness", Tesis de Doctorado, Scuola Superiore di Studi e Perfezionamento Sant' Ana, Pisa, 2007, pp. 199-230.

Kelley, C. R., "Agricultural production contracts: drafting considerations”, en The Hamline Law Review, Spring of 1995, Hamline University-Law School. Saint-Paul-MN, p. 2.

Kemelmajer de Carlucci, A., Fernández, S. y Herrera, M., "Bases para una relectura de la restricción a la capacidad civil en el nuevo Código”, La Ley, 18/08/15, p. 1.

Kemelmajer de Carlucci, A., "Código Civil y Comercial Comentado", Infojus, CABA, 2015, Tomo I, pp. XV y XVI.

López Alfonsín, M., Derecho Ambiental, Editorial Astrea, Buenos Aires, 2012, pp. 244-245.

Lorenzetti, P., Funciones de la responsabilidad civil y daño ambiental en el Proyecto de Código Civil y Comercial de la Nación de 2012, RCyS, 2013-VIII, 5, cita online: AR/DOC/2574/2013.

Lorenzetti, R. L., “La protección jurídica del ambiente”, en Revista La Ley, E-1463, 1997. 
Lorenzetti, R. L., Tratado de los Contratos. Parte General, Rubinzal Culzoni Editores, Buenos Aires, 2004, pp. 211-212.

Minot, N. W., Contract farming and its effect in small farmers in less developed countries, MSU International Development Papers, Working Paper $\mathrm{N}^{\circ}$ 31, Department of Agricultural Economics, Michigan State University, Michigan, 1986, pp. 13-14.

Moruzzi, L., Profili della vendita di prodotti agricoli con Prezzo a riferimetno e contratto di integrazione verticale, Giufrè Ed, Milano, 1962, pp. 61-62.

Novak, A., "Una cosa es una cosa y otra cosa es otra cosa. De daños ambientales individuales y colectivos”, en Revista La Ley Córdoba, 2015 (agosto), 736, cita online: AR/DOC/707/2015.

Palacios, P. Agroindustria Aviar Argentina, Ed. Imago Mundi, Buenos Aires, 2013. También en el Documento: "Complejo Avícola: Carne", octubre 2011, Serie "Producción Regional por Complejos Productivos". Secretaría de Política Económica. Subsecretaría de Producción Económica. Dirección Nacional de Programación Económica Regional. Ministerio de Economía y Finanzas Públicas.

Peck, A., State regulation to Production Contracts, Research Project, The National Agricultural Law Center, University Of Arkansas, 2006.

Pizarro, R. D., Tratado de Responsabilidad Objetiva, Thomson Reuters La Ley, Buenos Aires, 2015. Tomo II, cap. 32 app. 256.

Pizarro, R. D., "Responsabilidad civil por actividades riesgosas o peligrosas en el nuevo Código", en La Ley, 12/08/2015, p. 4.

Ruiz, H., "Contratos de Producción Agroindustrial. Principales características y reflexiones en torno a su utilización", en la Revista Actualidad y Prospectiva, de la Facultad de Ciencias Económicas de la UNNE, $\mathrm{N}^{\circ}$ 9, primavera 2012, pp. 105-106.

Teubal, M. y Pastore, R., "El Agro y los Complejos Agroindustriales: el caso argentino", en Teubal, M. (Dir), Globalización y expansión agroindustrial ¿Superación de la pobreza en América Latina?, Ed. Corregidor, Buenos Aires, 1995, pp. 107-135.

Tommaso, J. C., "La cebada cervecera en la Argentina", en Revista IDIA XXI Revista de Información sobre Investigación y Desarrollo Agropecuario, INTA Bordenave, Buenos Aires, 2004, Nº 6 , pp. 210 a 216.

Walsh, J., y Preuss, F., "El daño ambiental: La necesidad de nuevas instituciones jurídicas”, en Revista Jurisprudencia Argentina (JA: 1996-IV-962). 
